\title{
Health Promotion: A Critical Salutogenic Science
}

\author{
Jane Taylor (Gregg) ${ }^{1, *}$, Lily O’Hara ${ }^{2}$, Margaret Barnes ${ }^{3}$ \\ ${ }^{1}$ University of the Sunshine Coast, Sippy Downs Drive, Sippy Downs QLD 4558, Australia \\ ${ }^{2}$ College for Advanced Education, PO Box 126662, Abu Dhabi United Arab Emirates \\ ${ }^{3}$ University of the Sunshine Coast, Sippy Downs Drive, Sippy Downs QLD 4558 Australia \\ *Corresponding Author: JGregg@usc.edu.au
}

\begin{abstract}
Health promotion is a relatively new health science discipline focused on creating health and wellbeing at individual, group and population levels through health and health related policies and programs. Addressing inequities in the health of people via policies and programs that address the milieu of interrelated cultural, social, economic, and political determinants of health is at the heart of health promotion practice, and as such it is a political process. A critical and salutogenic approach characterises health promotion best-practice and is well established in the health promotion literature. However, the realisation of critical and salutogenic practice can be challenging for practitioners in an environment where biomedical and behavioural health paradigms dominate. Health promotion practitioners need to partner with and learn from other disciplines that have or share similar challenges. "Health promotion is everybody's business" is a catch cry in the field and conversations with others with similar ideals, values and principles about how to work together in the pursuit of health for all are needed.
\end{abstract}

Keywords Health Promotion, Salutogenic, Holistic, Ecological Science, Health Paradigms

\section{Introduction}

Health promotion is a critical applied science focused on creating health by addressing complex health issues and inequities at individual, community and population levels (Cottrell, Girvan, \& McKenzie, 2012; Lundy, 2010; Norman, 2009). Current complex health issues globally and locally include an ageing population, increased population density, under and over nutrition, rapid urbanisation, political violence, environmental change, economic policy, new and re-emerging infectious diseases, and chronic diseases (Baum, 2008; McMichael \& Butler, 2007; Mittelmark, 2007). These health issues, along with increasing health disparities within and between countries, are major challenges (Baum, 2008; Labonte, Schrecker \& Sen Gupta, 2005; Lundy, 2010) that require rigorous, systematic, and interdisciplinary responses.

As a formal discipline, health promotion is relatively new within the broader health sector and able to contribute to addressing such issues (Baum, 2008; Baum, Van Eyk, \& Hurley, 2006; McMichael \& Butler, 2007; Mittelmark, 2007; World Health Organisation, 1986, 1997). The theoretical knowledge base for health promotion derives from a range of disciplines including biological, behavioural, health, education, psychology, sociology, economic, environmental, and political sciences (Cottrell et al., 2012; Eriksson \& Lindstrom, 2008; Tremblay \& Richard, 2011). The basic concepts of health promotion are not new and there is evidence throughout human history of efforts to understand, create, protect, and promote the health and wellbeing of people (Baum, 2008; Cottrell et al., 2012; Tountas, 2009).

Well established health promotion concepts include a commitment to social justice and equity, holistic and ecological conceptions of health, addressing the complexity of individual level and environmental determinants of health, the empowerment and participation of people (International Union for Health Promotion and Education, 2007; Porter, 2006; Tremblay \& Richard, 2011), a salutogenic approach (Antonovsky, 1996; Robison, 2004; Robison \& Carrier, 2004) and evidence-based practice (Hulme-Chambers \& Walker, 2012; Lin \& Fawkes, 2007; McQueen, 2001; Nutbeam, 1996, 1999; Raphael, 2000; Rychetnik \& Wise, 2004). These concepts align with concepts of other critical science disciplines. However, there is some criticism within the health promotion field that health promotion still needs to establish its theoretical foundations to achieve its purported goals and aspirations (Antonovsky, 1996; Buchanan, 2006; Eriksson \& Lindstrom, 2008; Lowe, 2002; Lundy, 2010; Raphael, 2000; Tremblay \& Richard, 2011). Authors of this paper posit that to strengthen the discipline's theoretical foundations, greater attention to the realisation of the underlying critical and strength-based concepts, or values and principles (Gregg \& O'Hara, 2007a) of global strategic health promotion policies and charters is necessary. They also assert the need to learn from other disciplines that have chartered similar waters, for example, critical social science.

\section{Contemporary health promotion}

The universally accepted definition of health promotion as 
defined by the World Health Organisation (1986) states that health promotion is:

...the process of enabling people to increase control over, and to improve, their health. To reach a state of complete physical, mental and social wellbeing, an individual or group must be able to identify and realise aspirations, to satisfy needs, and to change or cope with the environment. Health is therefore, seen as a resource for everyday life, not the objective of living. Health is a positive concept emphasising social and personal resources, as well as physical capacities. Therefore, health promotion is not just the responsibility of the health sector, but goes beyond healthy lifestyles to wellbeing (p. 1).

Health promotion is a political and social change process with the core business of working with people across the life span to address the complex multiple determinants of health that impact on their lives (Allegrante, 2006; Buchanan, 2006; Eriksson \& Lindstrom, 2008; Frankish, Moulton, Rootman, Cole, \& Gray, 2006; Moloughney, 2006; Moodie \& Hulme, 2004; Norman, 2009). Combinations of educational, political, economic, and organisational actions are used to facilitate sustainable change in the behavioural, social, cultural, economic, political, and physical environmental determinants of health (Allegrante, Barry, Auld, Lamarre, \& Taub, 2009; Cottrell et al., 2012; McMichael \& Butler, 2007). Such changes increase the control people have over decisions about their health and wellbeing so that they can improve their health, and create supportive environments for people to live, work and play (Green \& Kreuter, 2005; World Health Organisation, 1986). Health promotion action can occur at individual, group, community or population levels, and is provided by a broad range of organisations within and outside the health sector, in multiple settings, and with diverse groups (Cottrell et al., 2012; Eriksson \& Lindstrom, 2008; Jirojwong \& Liamputtong, 2009; Lin \& Fawkes, 2007; Moodie \& Hulme, 2004).

\section{Health promotion practice}

There are a range of health promotion theories, models, and frameworks to guide practice, which commonly includes the four interrelated phases of needs assessment, planning, implementation, and evaluation. Needs assessment involves identifying the health needs of communities and determining priority health issues. Planning involves developing responses to priority issues by analysing issue determinants, developing goals and objectives, designing strategies and activities, assessing and sourcing resources, and developing evaluation plans. Implementation involves the actioning of change strategies and activities, and evaluating the processes involved in this action. Evaluation involves collecting and analysing qualitative and/or quantitative data to assess the short-term impact and long-term outcomes of a project (Green \& Kreuter, 2005; Hawe, Degeling, \& Hall, 1990; New South Wales Department of Health, 1994).

Each health promotion phase in itself is a discrete process but phases are not mutually exclusive. Practitioners are generally simultaneously involved in activity relevant to all phases, with more or less emphasis on different phases pending the stage of the project. The health promotion process also needs to be theory- and evidence-based, consider the social, cultural, and political contexts of those for whom programs are designed to benefit, be carried out with communities, and address issues of sustainability (Green \& Kreuter, 2005; McMichael \& Butler, 2007; New South Wales Department of Health, 1994; Swerissen \& Crisp, 2004).

\section{Health promotion approaches}

Health promotion approaches evident in contemporary health promotion practice include traditional and modern approaches (Gregg \& O'Hara, 2007a). Traditional health promotion is most common and refers to health promotion approaches underpinned by biomedical and behavioural health discourse and science. A biomedical health discourse is defined by medicine, and is concerned with improvements in physiological and psychological disease states via medical intervention and management. A behavioural health discourse is concerned with bringing about changes in people's risk taking behaviours, primarily through education strategies (Baum, 2008; Gregg \& O'Hara, 2007b; Robison \& Carrier, 2004).

The term 'modern health promotion' was initially coined by the WHO in 2006 to refer to the foundation concepts and principles established at the first global health promotion conference in Ottawa in 1986, and the resulting seminal health promotion document, the Ottawa Charter for Health Promotion (World Health Organisation, 2006). Modern health promotion reflects holistic and ecological health discourses and is concerned with addressing inequities, and developing a healthy functional ecosystem, which supports the health of people via changes in the full range of individual and environmental determinates of health (Gregg \& O'Hara, 2007b; Robison, 2004; Robison \& Carrier, 2004). A holistic definition of health ensures a focus on the physical, social, mental, and spiritual dimensions of health and wellbeing. An ecological definition of health acknowledges the multiple complex determinants of health and wellbeing, which requires a broad focus on people, their behaviours, their environments, and the connections between these factors (Baum, 2008; Robison \& Carrier, 2004). A salutogenic focus places emphasis on factors that create and support health and wellbeing rather than disease prevention and behavioural risk factors (Antonovsky, 1996; Eriksson \& Lindstrom, 2008; Gregg \& O'Hara, 2007b; Lindstrom \& Eriksson, 2006).

Health paradigms that reflect the scope of health discourses that have evolved since the $17^{\text {th }}$ Century include the biomedical health paradigm, the behavioural health paradigm, and the holistic, ecological, salutogenic health paradigm (Baum, 2008; Moulton, Frankish, Rootman, Cole, \& Gray, 2006; Robison \& Carrier, 2004). These paradigms differ in the way health is defined, the health issues and 
priorities addressed, the strategies implemented to improve or create health, and the criteria used to determine the success of strategies (Baum, 2008; Robison \& Carrier, 2004). Whilst traditional and modern health promotion approaches can be complementary, a modern health promotion approach is underpinned by critical and strengths-based concepts, and is necessary to address the complexity of health issues (Antonovsky, 1996; Baum, 2008; Gregg \& O'Hara, 2007b, 2007b; Robison \& Carrier, 2004).

\section{Critical and Strengths-based Concepts in Modern Health Promotion}

Health Inequity and Social Justice

Health inequity refers to the disparity in the health status of people within and between populations due to the unequal distribution of resources necessary for health (Baum, 2008; Bryant, 2010; Hulme-Chambers \& Walker, 2012; Tones \& Tilford, 2001). Groups of people are either advantaged or disadvantaged by policies and practices based on characteristics such as income, gender, race, sexual orientation, body size or shape, and mental and physical ability. Social justice lies at the heart of health promotion and is about fairness for all and ensuring the equitable distribution of social, economic and political resources, and opportunities to address inequities to improve health individually or collectively (Bryant, 2010; Hulme-Chambers \& Walker, 2012).

There is substantial evidence that disparities between people are increasing. Countries where resources such as income, housing and health care are more equitably distributed have better population health status than those where resources are inequitably distributed (Baum, 2008; Bryant, 2010). Bryant (2010) suggests that social and economic policies reflect the political ideologies of jurisdictions, and in countries where neo-liberalism is dominant, such as the US, Canada, UK and Australia, there is less investment in public social policy and greater health inequities. European nations that have rejected neo-liberalism and adopted public social policies to address determinants of health such as education, income, and housing experience greater health equity within their populations. Labonte et al. (2005) propose that economic globalisation has been a major contributor to inequities in health between countries, whereby wealthier countries are increasingly able to exploit poorer countries in the trade arena, which in turn has major implications for the distribution of resources for health.

Political ideology and the subsequent role of government and public policy therefore are critical in addressing inequities both within and between countries. Health promotion has a key role to advocate for and progress public policy that contributes to addressing health inequities (Baum, 2008; International Union for Health Promotion and Education, 2007). Health promotion also needs to prioritise working with communities that are most marginalised, vulnerable and disadvantaged, often referred to as 'hard to reach'. In practice however it is evident that much health promotion is not based on considerations of equity, rather a tendency to work with groups that are more visible or whole populations, or the less vulnerable and more accessible populations, often referred to as the 'worried well' (Baum, 2008).

\section{Salutogenesis}

Antonovsky first proposed the need for a salutogenic approach to health promotion in the 1990s (Antonovsky, 1996). The central tenet of salutogenic theory is a focus on the creation of health and understanding what causes health, rather than what causes disease (Antonovsky, 1996; Eriksson \& Lindstrom, 2008; Lindstrom \& Eriksson, 2006). Antonovsky identified two core concepts of salutogenesis as being fundamental to people being able to contend with life's challenges and experience quality of life outcomes (Lindstrom \& Eriksson, 2006). The first is General Resistance Resources (GRR) which are a range of psychosocial, biological and material factors, for example, money, knowledge, social relationships, self-esteem, culture and healthy behaviours that support people to perceive their lives in tangible and coherent ways (Lindstrom \& Eriksson, 2006). GRRs provide the basis for a Sense of Coherence (SOC), the second core concept, which refers to the ability of people on individual and collective levels to use GRRs to successfully comprehend and manage the complexities of life in meaningful ways (Antonovsky, 1996; Eriksson \& Lindstrom, 2008; Lindstrom \& Eriksson, 2006). Antonovsky (1996) and others (Eriksson \& Lindstrom, 2008; Lindstrom \& Eriksson, 2006) supportive of salutogenic theory propose salutogenesis to be synergistic with modern health promotion and therefore an appropriate approach for health promotion research and practice.

The emphasis on creating health, as distinct from preventing disease, is a consistent theme in the health promotion literature (Tones \& Tilford, 2001). For example, a salutogenic approach includes focusing on perceived health and happiness, purpose in life, spiritual connections, social support, a healthy ecosystem, physical resilience, optimism and hope, and the ability to experience emotions, in addition to addressing risk factors for poor health such as poverty, unemployment, disparity, powerlessness, isolation and discrimination. However, there is still significant investment in health promotion that is focused on limiting physical ill-health and/or that uses coercive or non-participatory processes (Baum, 2005). Salutogenic theory does not dismiss the importance of risk factors for disease, and acknowledges that diseases and their associated risk factors need to be addressed. However, modern health promotion needs to not only incorporate but go beyond disease frameworks to more fully understand and create health (Antonovsky, 1996; Lindstrom \& Eriksson, 2006). 


\section{A Holistic and Ecological Paradigm}

Understanding health holistically and ecologically is not a new concept and is commonplace for many Indigenous and eastern cultures. In western culture where objectivist science dominates, health is understood more commonly in biomedical terms, with emphasis on the physical dimensions of health in isolation from other dimensions of health. The limitations of such an approach, and the benefits of understanding health and wellbeing ecologically and holistically are well documented in the health promotion literature (Baum, 2008; Johnson \& Paton, 2008; Keleher, MacDougall \& Murphy, 2007; Robison, 2004).

A myriad of health promotion activists and authors have been progressing discourse and action for a more holistic and ecological approach to health for some decades (Butler, 2001; Kickbusch, 1997; Lowe, 2002; Robison \& Carrier, 2004; St Ledger, 2003). St Ledger (2003) broadly refers to this orientation as the incorporation of ecological perspectives into health constructs, necessary to address the complexity of the determinants of health issues of the day. Review of these perspectives highlights consistencies in terms of the interdependencies and relationships between the social, economic, and physical environments and human health on individual, community and population levels. Also highlighted are the complexities associated with broader more holistic, ecological approaches to improving health.

Ecological science provides greater insight into understanding such complexities (Robison \& Carrier, 2004) and draws on systems theory, which is concerned with how the component parts of a system interact and influence one another to affect the whole (Paton, Sengupta, \& Hassan, 2005; Robison \& Carrier, 2004; Ureda \& Yates, 2005; VanLeeuwen, Waltner-Toews, Abernathy, \& Smit, 1999). The two key concepts of systems theory are holism and complexity, which provide the lens to view problem situations in relation to the whole system whereby changes in one part of a system affect other parts of the system, with attention to the complexity of interactions and relationships (Barton, Emery, Flood, Selsky, \& Wolstenholme, 2004; Ife \& Tesoriero, 2006). Ecological science recognises that people exist in multiple ecosystems, from the individual level, to the family group, community and population level. It also acknowledges the interdependency of the components of the system, that all parts within the whole system affect each other, and that the whole is greater than the sum of the parts. For example, ecosystems theory can be used to understand the interactions between elements of the natural environment, such as air and water with plants, animals and humans. Using ecological science, it becomes apparent that health is determined by the interactions between people and their social, cultural, economic, political, natural and built environments, at individual, group, community and population levels (Cole, Eyles, Gibson, \& Ross, 1999; Green, Richard, \& Potvin, 1995; Nielsen, 2001; Robison \& Carrier, 2004; Stokols, 1992; VanLeeuwen et al., 1999). The participation of all stakeholders and multiple disciplines to address complex issues is also recognised in ecological science (Green et al., 1995; Nielsen, 2001). This calls for health promotion strategies that enable people to participate in decision-making processes about their own health and wellbeing.

\section{Empowerment}

Empowerment is described and discussed in the health promotion literature as both a process and an outcome, as well as occurring at individual, group, community and population levels (Baum, 2008; Ife \& Tesoriero, 2006; Moulton et al., 2006). Regardless of whether the focus of empowerment is at individual or collective levels, at the heart of empowerment as a process or outcome is the concept of power (Baum, 2008; Ife \& Tesoriero, 2006; Raeburn \& Rootman, 1998; Staples, 1990). Baum (2008) and McArdle (1999) emphasise the importance of understanding the notion of power at a theoretical level in designing, implementing and evaluating change strategies focused on improving the health and wellbeing of people, with emphasise on the risk associated with not considering power in terms of reinforcing and contributing to greater disempowerment.

Empowerment models and theories of power that have informed modern health promotion practice are drawn from the social sciences, and are concerned with the giving, redistribution, taking or acquiring of power to or by individuals or groups (Ife \& Tesoriero, 2006; Staples, 1990). As an outcome, empowerment is a reduction of the number of people that are powerless and an increase in the power of those that are disadvantaged (Baum, 2008; Ife \& Tesoriero, 2006). It is widely acknowledged that individual level empowerment or self-empowerment is a pre-determinant or foundation for empowerment at the community level (Baum, 2008; McArdle, 1999; Tones \& Tilford, 2001). Baum (2008) suggests that power, and where it lies within a community, is an indicator of whose interests are being served in a health promotion initiative, for example, lay community, government and non-government organisations, political interests.

In practice therefore, priority consideration needs to be on ensuring non-maleficence and maximum benefit of health promotion action. That is, there must be critical consideration of the potential benefits and harms of an initiative with priority to "do no harm". This includes considering who may be harmed by change processes and in what way, taking steps to minimise or avoid harm, and communicating risks involved in a truthful and open manner rather than assuming that health promotion will result in positive health outcomes. Also important is the need to respect the personal autonomy of people to make decisions for themselves, irrespective of whether as practitioners we agree with the appropriateness of those decisions (Baum, 2008; Robison \& Carrier, 2004; Sindall, 2002; Tountas, 2009). 


\section{Participation}

Like empowerment, participation can be understood as a process and an outcome, and occurring at different levels. Baum (2008) suggests that at an individual level, participation works as a process of personal empowerment. At a program level, the participation of stakeholders ensures the relevance and therefore effectiveness of health promotion initiatives. Participation as an outcome is concerned with the achievement of empowerment and self-determination by those who are the least powerful and most often the poorest (Baum, 2008; McArdle, 1999; Walt \& Rifkin, 1990).

In a health promotion context, Walt and Rifkin (1990) describe participation as a mechanism for actively engaging local people or the intended beneficiaries of health promotion programs in decision-making processes about their health and wellbeing (Walt \& Rifkin, 1990). Decision-making is a key element through which participation is realised. Discourse pertaining to participation consistently highlights the need for meaningful participation of all stakeholders in health promotion programs; a precursor for people to contribute to decision-making processes about that which is important to them (Baum, 2008; Ife, 2000; Labonte, 1996; McArdle, 1999; Raeburn \& Rootman, 1998).

A range of authors (Baum, 2008; Ife \& Tesoriero, 2006; Labonte, 1996; McArdle, 1999; O'Connor-Fleming \& Parker, 2007; Raeburn \& Rootman, 1998) advocate that meaningful participation by people in decision-making requires a grass roots approach, and that it is only through such processes that people feel empowered to partake in shaping their own health and wellbeing. In health promotion, community-based programs and the ecological health promotion approach place most emphasis on the need to ensure the active participation of all stakeholders (Judd, Frankish, \& Moulton, 2001; Labonte, 1996; Raeburn \& Rootman, 1998).

Baum (2008) posits that increased focus on the participation of people in a range of political and social movements over the past four decades is paralleled in the health field. Even so, there has been much criticism about how meaningful the participation of people in decision-making in planning for the health and wellbeing of their local communities has been. The perceived dissonance between participation rhetoric and reality is largely related to differentials in power amongst stakeholders in an initiative, which might include communities, non-government and government organisations, political agendas and practitioners (Ife, 2000; McArdle, 1999).

In principle, the idea of mobilising participation that best serves the interests of the community, with emphasis on those who are most marginalised and poorest, appears relatively straightforward. In practice however, this task is fraught with challenges (Baum, 2008; Botes \& Renesburg, 2000). In order to facilitate an empowering participation process that addresses the real needs of the community, it is critical that health promotion practitioners have an understanding about such challenges and the form of participation that they are working with, and as a result that they employ strategies that maximise opportunities for meaningful participation.

A primary barrier to facilitating genuine participation is the dominance of the biomedical and behavioural health paradigms over the ecological and holistic health paradigm (Antonovsky, 1996; Baum, 2008; Robison \& Carrier, 2004). Another barrier derives from health promotion being a political process (Baum, 2008; Ife, 2000; Raeburn \& Rootman, 1998) that requires a shift in internal and external power structures to impact the health and wellbeing of communities. If not facilitated with care, health promotion processes can result in the reinforcement of existing power structures and further marginalisation of those with the least power (Ife, 2000; McArdle, 1999).

Baum (2008) proposes a four stage continuum for participation, which is a useful framework for practitioners to identify the form of participation that is being facilitated. The first form of participation in the continuum is 'consultation as a means', which involves organisations outside the community asking for community opinions about predetermined policies and plans. The second form is 'participation, participation', which involves organisations outside the community using participation to achieve a predefined outcome. The third form is 'substantive participation', where participation is initiated and lead by outsiders, but local people are engaged in determining priorities and implementation. The fourth form, 'structural participation', involves the community controlling the development process, even if it was initiated from outside the community. The benefit of practitioners being able to identify the form of participation that is being facilitated or possible enables them to be more transparent about their practice. It also reduces the possibility of creating harm by not raising unrealistic expectations or contributing either unconsciously or consciously to any social, cultural or political systems that further marginalise the least empowered (Baum, 2008).

\section{Evidence-based practice}

Evidence-based practice refers to the use of good quality, appropriate and credible information to make decisions about health promotion priorities, programs, and policies that have sustainable outcomes (Hulme-Chambers \& Walker, 2012; Nutbeam, 1996; Raphael, 2000; Rychetnik \& Wise, 2004). For example, epidemiological research assists in identifying priority health issues and their causes (Baum, 2008; Fanany, 2012), and evaluation research assists in assessing the effectiveness and efficiency of health promotion action (Tones \& Tilford, 2001). The evidence for health promotion is growing, and draws on many other fields and methods, including research methods to undertake research and evaluation. Health promotion practitioners and researchers are required to base their work on evidence, and contribute to developing the evidence-base through the evaluation of programs and policies (International Union for Health Promotion and Education, 2007; McQueen, 2001; 
Nutbeam, 1996; Rowling \& Jeffreys, 2006; Rychetnik \& Wise, 2004).

Rychetnik and Wise (2004) assert that there has been considerable progress in producing evidence for use in health promotion research and practice via the conduct and availability of systematic reviews, such as those carried out by the Cochrane Collaboration. They also suggest that there is considerable evidence related to the aetiology and magnitude of health issues, as well as health inequities, and growing evidence on the effectiveness of programs focused on affecting the behavioural risk factors for ill health. However there is much less evidence on the effectiveness of programs to address the broader determinants of health and how best to reduce inequities (Rychetnik \& Wise, 2004).

Lin and Fawkes (2007) suggest that the evidence-base on the effectiveness of programs is somewhat limited due to minimal investment in the evaluation element of health promotion practice and research, and the inadequacy of information systems to link health related data to health promotion programs (Lin \& Fawkes, 2007). McQueen (2000) emphasises challenges associated with producing evidence that reflects the complexities of health, as well as the multi-disciplinary nature of health promotion (McQueen, 2000). Nutbeam (1999) and McQueen (2001) both advocate for strengthening the evidence-base for health promotion, with particular attention to broadening the scope of evaluation approaches and methods beyond those appropriate for biomedical and behavioural type interventions, to those appropriate for community-based health promotion approaches, and addressing the complexities of health. Tones and Tilford (2001) caution that health promotion is a young discipline, therefore, ' $\ldots$ it is premature to be too prescriptive about what should or should not constitute health promotion evaluation' (p.188). They advocate for the use of a combination of research designs, and qualitative and quantitative methods relevant to the complexity and nature of the issues being addressed (Tones \& Tilford, 2001).

\section{Conclusion}

Reflection on the progress of health promotion since the Ottawa Charter (World Health Organisation, 1986) by leading public health and health promotion scholars has highlighted key health challenges for the discipline if it is to achieve its goals and aspirations. The first challenge is the widening of the gap between the rich and the poor both within and between countries, and decreases in life expectancy in some parts of the world, which indicates that health promotion action has not been effective in contributing to addressing the economic and social determinants of health (Antonovsky, 1996; Baum, 2008; Catford, 2004; Lin \& Fawkes, 2007; McMichael \& Butler, 2007). The second challenge is the broadening scope of health issues such as chronic and infectious diseases, injury and environmental threats, which in theory are largely amenable to improvement through policies for social and physical infrastructure that create health (Antonovsky, 1996; McMichael \& Butler, 2007). The ongoing positioning of health promotion within the dominant disease prevention framework, as distinct from focusing on factors that create health, has in part contributed to these health challenges (Antonovsky, 1996; Eriksson \& Lindstrom, 2008; Hauge \& Einar-Hem, 2011).

Health promotion has a key role in contributing to reducing inequities within and between populations by addressing the interrelated complexities of individual and environmental health determinants (Baum, 2008; Bryant, 2010; Hulme-Chambers \& Walker, 2012; Tones \& Tilford, 2001). This requires practitioners to understand health holistically and ecologically, and to develop sustainable programs and policies that are evidence-based (Hulme Chambers \& Walker, 2012; Nutbeam, 1996; Raphael, 2000; Rychetnik \& Wise, 2004), salutogenic (Antonovsky, 1996; Eriksson \& Lindstrom, 2008; Lindstrom \& Eriksson, 2006), and inclusive of key concepts such as empowerment (Baum, 2008; Ife \& Tesoriero, 2006; Itzhaky \& York, 2002; Moulton et al., 2006; Raeburn \& Rootman, 1998; Staples, 1990) and participation (Baum, 2008; Ife, 2000; Labonte, 1996; McArdle, 1999; Raeburn \& Rootman, 1998). However this critical and strengths orientation continues to be difficult to achieve, due to the dominance of biomedical and behavioural approaches to health. It is essential therefore, that health promotion practitioners partner with and learn from other disciplines that share similar challenges. "Health promotion is everybody's business" is a catch cry in the field and we need conversations with others with similar ideals, values and principles about how we work together in the pursuit of health for all.

\section{REFERENCES}

Allegrante, J. (2006). In search of a new ethic for health promotion. Health Education and Behavior, 33(3), 305-307.

Allegrante, J., Barry, M., Auld, E., Lamarre, M.-C., \& Taub, A. (2009). Toward international collaboration on credentialing in health promotion and health education: The Galway Consensus Conference. Health Education Behaviour, 36(3), 427-438.

Antonovsky, A. (1996). The salutogenic model as a theory to guide health promotion. Health Promotion International, 11(1), 11-18. doi: 10.1093/heapro/11.1.11

Barton, J., Emery, M., Flood, R., Selsky, J., \& Wolstenholme, E. (2004). A maturing of systems thinking? Evidence from three perspectives. Systemic Practice and Action Research, 17(1), 3-35.

Baum, F. (2005). Who cares about health for all in the 21 st century? Journal of Epidemiology and Community Health, 59, 714-715.

Baum, F. (2008). The New Public Health (3rd ed.). South Melbourne: Oxford University Press.

Baum, F., Van Eyk, H., \& Hurley, C. (2006). Re-orientation of health services towards health promotion: An Australian case study 
of aborted health service reform. Australian Journal of Primary Health, 12(2), 24-33.

Botes, L., \& Renesburg, D. (2000). Community participation in development: Nine plagues and twelve commandments. Community Development Journal, 35(1), 41-48.

Bryant, T. (2010). Promoting health equity through political action. Social Alternatives, 29(2), 57-63.

Buchanan, D. (2006). A new ethic for health promotion: Reflections on a philosophy of health education for the 21 st century. Health Education and Behaviour, 33(3), 290-304.

Butler, J. (2001). Principles of health education and health promotion (3 ed.). USA: Wadsworth Thomson Learning.

Catford, J. (2004). Health promotion's record card: How principled are we 20 years on? Health Promotion International, 19(1), 1-4.

Cole, D., Eyles, J., Gibson, B., \& Ross, N. (1999). Links between humans and ecosystems: The implications of framing for health promotion strategies. Health Promotion International, 14(1), 65-72.

Cottrell, R., Girvan, J., \& McKenzie, J. (2012). Principles and foundations of health promotion and education (5th ed.). San Francisco: Pearson.

Eriksson, M., \& Lindstrom, B. (2008). A salutogenic interpretation of the Ottawa Charter. Health Promotion International, 23(2), 190-199.

Fanany, R. (2012). Introduction to epidemiology. In $P$. Liamputtong, R. Fanany \& G. Verrinder (Eds.), Health, illness and well-being: Perspectives and social determinants. Melbourne: Oxford University Press.

Frankish, C., Moulton, G., Rootman, I., Cole, C., \& Gray, D. (2006). Setting a foundation: Underlying values and structures of health promotion in primary health care settings. Primary Health Care Research and Development, 7, 172-182.

Green, L., \& Kreuter, M. (2005). Health program planning: An educational and ecological approach (4 ed.). New York: McGraw Hill.

Green, L., Richard, L., \& Potvin, L. (1995). Ecological foundations of health promotion. American Journal of Health Promotion, 10(4), 270-281.

Gregg, J., \& O'Hara, L. (2007a). Values and principles evident in current health promotion practice. Health Promotion Journal of Australia, 18(1), 7-11.

Gregg, J., \& O'Hara, L. (2007b). The Red Lotus Health Promotion Model: A new model for holistic, ecological, salutogenic health promotion practice. Health Promotion Journal of Australia, 18(1), 12-19.

Hauge, H., \& Einar-Hem, H. (2011). Developing health promotion education: Mainstreaming or acknowledging tensions in an evolving discipline? Scandinavian Journal of Public Health, 39(6), 79-84.

Hawe, P., Degeling, D., \& Hall, J. (1990). Evaluating health promotion: A health worker's guide. Sydney: Maclennan and Petty.

Hulme-Chambers, A., \& Walker, R. (2012). Introduction to health promotion. In P. Liamputtong, R. Fanany \& G. Verrinder (Eds.), Health, illness and well-being: Perspectives and social determinants. Melbourne: Oxford Univerity Press.
Hulme Chambers, A., \& Walker, R. (2012). Introduction to health promotion. In P. Liamputtong, R. Fanany \& G. Verrinder (Eds.), Health, illness and well-being: Perspectives and social determinants. South Melbourne: Oxford Univerity Press.

Ife, J. (2000). Community development: Community based alternatives in an age of globalisation. South Melbourne: Longman.

Ife, J., \& Tesoriero, F. (2006). Community development: Community-based alternatives in an age of globalisation (3 ed.). Frenchs Forest: Pearson Education Australia.

International Union for Health Promotion and Education. (2007). Shaping the future for health promotion: Priorities for action. International Union for Health Promotion and Education Retrieved from http://www.iuhpe.org/.

Itzhaky, H., \& York, A. (2002). Showing results in community organisation. Social Work New York, 47(2), 125-132.

Jirojwong, S., \& Liamputtong, P. (Eds.). (2009). Population health, communities and health promotion. South Melbourne: Oxford University Press.

Johnson, A., \& Paton, K. (2008). Health promotion and health services: Management for change. South Melbourne: Oxford University Press.

Judd, J., Frankish, J., \& Moulton, G. (2001). Setting standards in the evaluation of community-based health promotion programmes-a unifying approach. Health Promotion International, 16(4), 367-380. doi: $10.1093 /$ heapro/16.4.367

Keleher, H., MacDougall, C., \& Murphy, B. (Eds.). (2007). Understanding health promotion. South Melbourne: Oxford University Press.

Kickbusch, I. (1997). Think health: What makes the difference? Health Promotion International, 12(4), 265-272. doi: 10.1093/heapro/12.4.265

Labonte, R. (1996). Health Promotion Training Manual. . Brisbane: University of Queensland.

Labonte, R., Schrecker, T., \& Sen Gupta, A. (2005). Health for some: Death, disease and disparity in a globalising era. Toronto: Centre for Social Justice.

Lin, V., \& Fawkes, S. (2007). Health promotion in Australia: Twenty years on from the Ottawa Charter. IUHPE - Promotion and Education, 14(4), 203-208.

Lindstrom, B., \& Eriksson, M. (2006). Contextualizing salutogenesis and Antonovsky in public health development. Health Promotion International, 21(3), 238-244.

Lowe, I. (2002). Ecological health promotion: some principles. Health Promotion Journal of Australia, 13(1), 5-9.

Lundy, T. (2010). A paradigm to guide health promotion into the 21st century: The integral idea whose time has come. Global Health Promotion, 17(3), 44-53.

McArdle, J. (1999). Community development in the market economy. Melbourne: Vista Publications.

McMichael, A., \& Butler, C. (2007). Health promotion challenges Emerging health issues: The widening challenge for population health promotion. Health Promotion International, 21(1), 15-24.

McQueen, D. (2000). Perspectives on health promotion: Theory, evidence, practice and the emergence of complexity. Health 
Promotion International, 15(2), 95-97.

McQueen, D. (2001). Strengthening the evidence base for health promotion. Health Promotion International, 16(3), 261-268. doi: 10.1093/heapro/16.3.261

Mittelmark, M. (2007). Shaping the future of health promotion: Priorities for action. Health Promotion International, 23(1), 98-102.

Moloughney, B. (2006). Development of a discipline-specific competency set for health promoters: Findings from a review of the literature. Ontario: BWM Health Consultants Inc.

Moodie, R., \& Hulme, A. (Eds.). (2004). Hands-on health promotion. Melbourne: IP Communications.

Moulton, G., Frankish, C., Rootman, I., Cole, C., \& Gray, D. (2006). Building on a foundation: Strategies, processes and outcomes of health promotion in primary health care settings. Primary Health Care Research and Development, 7(3), 269-277.

New South Wales Department of Health. (1994). Program management guidelines for health promotion. Sydney: New South Wales Department of Health.

Nielsen, N. (2001). Ecosystem approaches to human health. Cad. Saude Publica, Rio de Janeiro, 17, 69-75.

Norman, C. (2009). Health promotion as a systems science and practice. Journal of Evaluation in Clinical Practice, 15, 868-872.

Nutbeam, D. (1996). Achieving 'best practice' in health promotion: Improving the fit between research and practice. Health Education and Research, 11(3), 317-326.

Nutbeam, D. (1999). The challenge to provide 'evidence' in health promotion. Health Promotion International, 14(2), 99-101. doi: 10.1093/heapro/14.2.99

O'Connor-Fleming, M., \& Parker, E. (2007). Health promotion: Principles and practice in the Australian context (3rd ed.). Sydney Allen and Unwin.

Paton, K., Sengupta, S., \& Hassan, L. (2005). Settings, systems and organisation development: The Healthy Living and Working Model. Health Promotion International, 20(1), 81-89.

Porter, C. (2006). Ottawa to Bangkok: Changing health promotion discourse. Health Promotion International, 22(1), 72-79. doi: 10.1093/heapro/da1037

Raeburn, J., \& Rootman, I. (1998). People-centred health promotion. Chichester: John Wiley and Sons.

Raphael, D. (2000). The question of evidence in health promotion. Health Promotion International, 15(4), 355-367. doi: 10.1093/heapro/15.4.355

Robison, J. (2004). Toward a new science: A new model for health promotion focuses on a true underdstanding of health and healing, seeking optimal wellness by incorporating all dimensions of the human experience. WELCOA's Absolute Advantage Magazine, 3, 2-5.

Robison, J., \& Carrier, K. (2004). The spirit and science of holistic health: More than brocolli, jogging and bottled water...More than yoga, herbs and meditation. Indiana: Authorhouse.

Rowling, L., \& Jeffreys, V. (2006). Capturing complexity: Integrating health and education research to inform health-promoting schools policy and practice. Health Education Research, 21(5), 705-718.

Rychetnik, L., \& Wise, M. (2004). Advocating evidence-based health promotion: Reflections and a way forward. Health Promotion International, 19(2), 247-257.

Sindall, C. (2002). Does health promotion need a code of ethics? Health Promotion International, 17(3), 201-203. doi: 10.1093/heapro/17.3.201

St Ledger, L. (2003). Health and nature: New challenges for health promotion. Health Promotion International, 18(3), 173-175.

Staples, H. (1990). Powerful ideas about empowerment. Administration in Social Work, 14(2), 29-42.

Stokols, D. (1992). Establishing and maintaining healthy environments: Toward a social ecology of health promotion. American Psychologist, 47(1), 6-22.

Swerissen, H., \& Crisp, B. (2004). The sustainability of health promotion interventions for different levels of social organisation. Health Promotion International, 19(1), 123-130.

Tones, K., \& Tilford, S. (2001). Health promotion: Effectiveness, efficiency and equity ( $3 \mathrm{rd}$ ed.). Cheltenham: Nelson Thornes.

Tountas, Y. (2009). The historical origins of the basic concepts of health promotion and education: The role of ancient Greek philosophy and medicine. Health Promotion International, 24(2), 185-192.

Tremblay, M., \& Richard, L. (2011). Complexity: A potential paradigm for a health promotion discipline. Health Promotion International. doi: 10.1093/heapro/dar054

Ureda, J., \& Yates, S. (2005). A systems view of health promotion. Journal of Health and Human Services Administration, 28(1/2), $5-38$.

VanLeeuwen, J., Waltner-Toews, D., Abernathy, T., \& Smit, B. (1999). Evolving models of human health toward an ecosystem context. Ecosystem Health, 5(3), 204-219.

Walt, G., \& Rifkin, S. (1990). The political context of primary health care. In P. Streefland \& J. Chabot (Eds.), Implementing primary health care (pp. 13-20). Amsterdam: Royal Tropical Institute.

World Health Organisation. (1986). Ottawa Charter for Health Promotion: First international conference on health promotion. Geneva: WHO.

World Health Organisation. (1997). Jakarta Declaration for Health into the 21 st Century. Geneva: WHO.

World Health Organisation. (2006). Health promotion in a globalised world: Report by the secretariat. Geneva: WHO. 